\title{
Appropriateness of liver biopsy
}

\author{
Thierry Poynard MD PhD ${ }^{1}$, Vlad Ratziu MD ${ }^{1}$, Pierre Bedossa MD PhD ${ }^{2}$
}

T Poynard, V Ratziu, P Bedossa. Appropriateness of liver biopsy. Can J Gastroenterol 2000;14(6):543-548. This review aims to discuss the appropriateness of liver biopsy in two frequent liver diseases, hepatitis $\mathrm{C}$ and alcoholic liver disease. The medical literature, published between 1965 and 1999, was reviewed by using MEDLINE . Only $0.1 \%$ of the publications were devoted specifically to the appropriateness of liver biopsy. Not all studies observed a significant agreement among doctors on the decision to use liver biopsy. Therefore, there is a possibility that hepatologists have significant, heterogeneous opinions concerning the appropriateness of liver biopsy.

Appropriateness should be evaluated for different techniques such as percutaneous liver biopsy, guided or not by ultrasonography, and the types of needles, automatic or not. The present paper reviews the evaluation of liver biopsy appropriateness in the real world, the adverse events and mortality of liver biopsy, and the appropriateness of liver biopsy in alcoholic liver disease and chronic hepatitis C.

The authors conclude that liver biopsy is used extensively, but its appropriateness has not been evaluated perfectly. Therefore, further evaluation of the appropriateness of liver biopsy in the practical algorithm of such diseases is needed.

Key Words: Alcoholic liver disease; Hepatitis C; Liver biopsy; Liver biopsy appropriateness

\section{L'utilité de la biopsie du foie}

RÉSUMÉ : Le but de cette revue est de discuter l'utilité de la biopsie du foie dans deux maladies fréquentes du foie que sont l'hépatite $\mathrm{C}$ et l'hépatopathie alcoolique. Une revue de la littérature scientifique publiée entre 1965 et 1999 a été pratiquée à l'aide de Medline. Seule une des 1000 publications portait spécifiquement sur l'utilité de la biopsie du foie. Certaines études révélaient des discordances parmi les médecins quant aux indications de la biopsie du foie. Par conséquent, il se peut que les hépatologues aient des opinions grandement divergentes sur l'utilité de la biopsie du foie.

L'utilité de cette intervention devrait être évaluée séparément pour les différentes techniques utilisées telles que la biopsie hépatique percutanée guidée ou non guidée par échographie, le type d'aiguilles et le procédé automatique ou manuel. Le présent article passe en revue l'évaluation des études portant sur l'utilité, en pratique courante, de la biopsie du foie, les événements indésirables, y compris la mortalité, liés à cette intervention et son utilité dans l'hépatopathie alcoolique et l'hépatite C chronique.

Les auteurs concluent que la biopsie du foie est très pratiquée, mais que son utilité n'a pas été parfaitement évaluée. Par conséquent, il est nécessaire de procéder à une évaluation plus poussée de l'utilité de la biopsie du foie dans l'algorithme de prise en charge de telles maladies.
$\mathrm{F}$ or hepatologists, liver biopsy is considered an essential procedure to aid in making rational decisions (1). For patients and general practitioners, it may be considered an aggressive procedure (2). Therefore, there is a risk that treatment will be reduced in frequently occuring diseases such as chronic hepatitis C, where liver biopsy is considered mandatory for making treatment decisions.

This review aims to discuss the appropriateness of liver biopsy in two frequent liver diseases, hepatitis $\mathrm{C}$ and alcoholic liver disease.

This mini-review was prepared from a presentation made at the World Congress of Gastroenterology in Vienna, Austria, September 6 to 11, 1998

${ }^{1}$ Service d'Hépato-Gastroentérologie Groupe Hospitalier Pitié-Salpêtrière, Paris, ${ }^{2}$ Service d'Anatomie Pathologique, Hôpital de Bicètre, France

Correspondence and reprints: Dr Thierry Poynard, Service d'Hépato-Gastroentérologie, Groupe Hospitalier Pitié-Salpêtrière 47-83 Boulevard de

l'Hôpital, 75651, Paris Cedex 13. Telephone +33-1-42-16-10-02, fax +33-1-45-86-20-22, e-mail tpoynard@teaser.fr

Received for publication June 7, 1999. Accepted June 9, 1999 


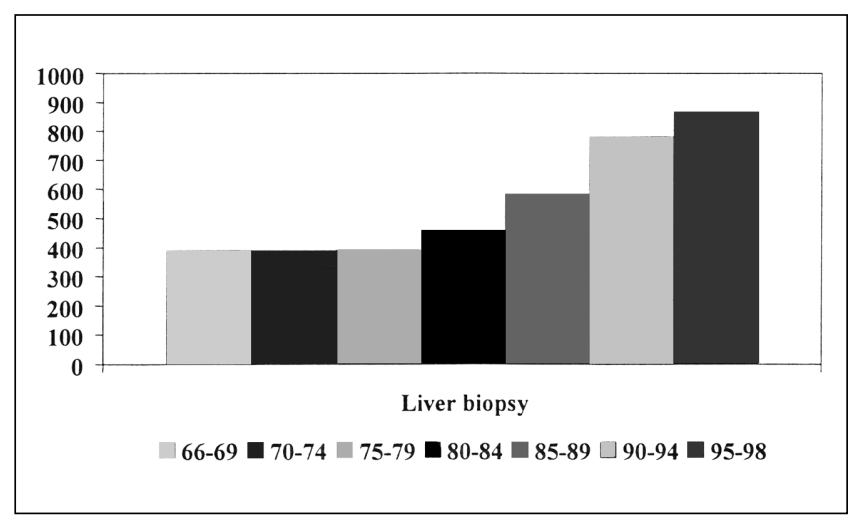

Figure 1) Incidence per year of publications relating to liver biopsy (MEDLINE)

\section{HISTORY OF LIVER BIOPSY: A 117-YEAR-OLD PROCEDURE - IS ITS SURVIVAL PROOF OF ITS APPROPRIATENESS?}

The introduction of liver biopsy in the literature is attributed to Ehrlich (3) in 1883. Ehrlich was quoted later by von Frerichs (3), and his results appeared with the first series of biopsies published in 1907 (4). The first evaluation was published in 1935 by Huard (5), but a hallmark in the professionalization of this technique was the publication by Menghini (6) of his famous needle in 1958.

We reviewed the medical literature by using MEDLINE and showed that the incidence of publications concerning liver biopsy (Figure 1) was stable in the 1960s and 1970s, with around 400 per year, and increased thereafter. In the past five years, 800 publications per year have concerned liver biopsy.

Among these publications, only $0.1 \%$ were devoted specifically to the appropriateness of liver biopsy. This discrepancy raises the following hypotheses: hepatologists believe that liver biopsy is appropriate and, therefore, have more important things to do; or they do not care about appropriateness.

A pioneer study by Theodossi et al (7) favours the first hypothesis. They observed a significant agreement among doctors on the decision to use liver biopsy. Kappa concordance tests were significant on the following items: the decision is made to perform the biopsy (kappa $=0.42)$; the biopsy is not necessary (kappa $=0.41$ ); the biopsy is wanted and considered safe (kappa $=0.52)$; the findings are likely to be helpful but the potential risks outweigh the benefits (kappa $=0.36)$; and the biopsy is necessary despite the risks ( $\mathrm{kappa}=0.38$ ). On the other hand, these agreements and estimates are far from perfect $(\mathrm{kappa}=1.00)$. This raises the possibility that hepatologists have significant, heterogeneous opinions concerning the appropriateness of liver biopsy.

\section{THE IDEAL EVALUATION OF LIVER BIOPSY APPROPRIATENESS}

Ideally, the evaluation of appropriateness would include the prevalence of defined liver diseases, definition of histological signs (sensitivity, specificity, receiver operating characteris- tic curves, predictive values), diagnostic value of these signs, applicability, adverse events, cost, efficacy and utility. Appropriateness should be evaluated for different techniques such as percutaneous liver biopsy, guided or not by ultrasonography, and the type of needles, automatic or not.

\section{THE EVALUATION OF LIVER BIOPSY APPROPRIATENESS IN THE REAL WORLD}

When the appropriateness is controversial among experts, there is certainly a place for evaluation.

In the real world, there are probably some clinical situations where the appropriateness or nonappropriateness is so obvious that the evaluation is inappropriate.

From a clinical point of view, biopsy is appropriate when a therapeutic decision or a diagnostic decision depends on the liver histology. Biopsy is not appropriate when there is no therapeutic decision or diagnostic decision that depends on the liver histology.

Concordance among pathologists, techniques and sampling errors: Several chronic liver disease studies have evaluated the intra- and interobserver (pathologist) concordance (8$11)$, the discordances among methods (12-16) and the sampling errors $(8,17)$. For both alcoholic and viral chronic liver disease, there were significant concordance values for standardized items, particularly for fibrosis staging (9-12).

Four randomized trials compared different biopsy methods (13-16). For the diagnosis of cirrhosis, one trial observed better sensitivity of laparoscopy versus percutaneous biopsy (13), and another trial observed a better sensitivity of the Tru-Cut (Tru-Cut, London, United Kingdom) versus the Menghini needle (14). One trial observed larger sampling and fewer adverse events with the ultrasound-guided, anterior, large bore cutting needle biopsy than with the intercostal Menghini technique (15). Another trial observed fewer adverse events when ultrasound-guided biopsy was used ( $2 \%$ versus $9 \% ; \mathrm{P}<0.05)$ no matter which needle was used (16).

Few studies have assessed the sampling variability. When three percutaneous biopsies were performed in 75 patients through a single entry site, the overall concordance rate was only $51 \%$ (17). When laparoscopic biopsy from the right lobe was compared with biopsy of the left lobe in 80 alcoholic patients, the overall concordance rate was $70 \%$, including $73 \%$ for the staging of fibrosis (12).

Recently, the standards of a normal liver were revisited (18-19) because no scoring system had integrated a definition of normal liver structure in its own definition.

\section{ADVERSE EVENTS AND MORTALITY OF LIVER BIOPSY}

Published articles (with more than 200 patients) assessing severe adverse events and mortality rates are summarized in Table 1 (20-28). There was a significant heterogeneity among the observed mortality rates for biopsy, ranging from 0 to 0.33 deaths per 1000 biopsies. Risk factors identified were older age and cirrhosis. 
Table 1

Uncontrolled observations of adverse events and mortality associated with liver biopsy

\begin{tabular}{|c|c|c|c|c|c|c|c|c|c|c|}
\hline \multirow[b]{2}{*}{ Author, year (reference) } & \multirow{2}{*}{$\begin{array}{c}\text { Number } \\
\text { of } \\
\text { patients }\end{array}$} & \multirow[b]{2}{*}{ Type of biopsy } & \multirow[b]{2}{*}{ Design } & \multirow[b]{2}{*}{$\begin{array}{c}\text { Adverse events } \\
\text { definition }\end{array}$} & \multicolumn{4}{|c|}{ Severe adverse events } & \multicolumn{2}{|c|}{ Mortality } \\
\hline & & & & & $\mathbf{n}$ & $\mathrm{n} / \mathbf{1 0 0 0}$ & $95 \% \mathrm{Cl}$ & $\mathbf{n}$ & n/1000 & $95 \% \mathrm{Cl}$ \\
\hline Gayral et al, 1979 (20) & 2346 & $\begin{array}{l}\text { Laparoscopy, } \\
\text { percutaneous, } \\
\text { surgery }\end{array}$ & Retrospective & Bleeding & 11 & 4.7 & $2.3-8.4$ & 4 & 1.7 & $0.5-4.4$ \\
\hline McGill et al, 1990 (23) & 9212 & Percutaneous & Retrospective & Bleeding & 22 & 2.4 & $1.5-3.6$ & 10 & 1.1 & $0.5-2.0$ \\
\hline Maharaj et al, 1992 (24) & 2646 & Percutaneous & Prospective & $\begin{array}{c}\text { Bleeding, } \\
\text { pneumothorax, } \\
\text { biliary peritonitis, } \\
\text { pain }\end{array}$ & 63 & 24 & $18-30$ & 8 & 3.0 & $1.3-5.9$ \\
\hline Janes et al, 1993 (26) & 405 & $\begin{array}{l}\text { Percutaneous } \\
\text { outpatients }\end{array}$ & Retrospective & Admission & 13 & 32 & $17-54$ & 0 & 0.0 & $0.0-9.1$ \\
\hline Gilmor et al, 1995 (27) & 1500 & Percutaneous & Retrospective & Bleeding & 26 & 17 & $11-25$ & 5 & 3.3 & $1.1-7.8$ \\
\hline Vivas et al, 1998 (28) & 378 & Percutaneous & Prospective & $\begin{array}{l}\text { Admissions } \\
\text { and bleeding }\end{array}$ & 7 & 19 & $7-38$ & 0 & 0.0 & $0.0-9.7$ \\
\hline Total & 98,445 & & & & 306 & 3.1 & $2.8-3.5$ & 33 & 0.3 & $0.2-0.5$ \\
\hline
\end{tabular}

\section{APPROPRIATENESS OF LIVER BIOPSY IN ALCOHOLIC LIVER DISEASE}

Extremely simple view: In alcoholic liver disease, biopsy can be viewed as inappropriate when alcohol consumption is elevated and liver tests are abnormal. Whatever the biopsy's result, the clinical decision will be to recommend alcohol abstinence.

Intermediate point of view: In fact, things are more complicated, and biopsy can be appropriate for making therapeutic decisions. In patients with alcoholism and severe liver disease, biopsy is necessary in order to decide whether corticosteroid treatment is necessary. Seventy per cent of patients with alcoholism with severe liver disease have acute alcoholic hepatitis (MADDREY index higher than 32 - that is patients with jaundice and severe impairment of prothrombin time). Randomized trials have shown that 28 days of corticosteroid treatment improves the survival of patients with acute alcoholic hepatitis (29-31).

Biopsy may be viewed as necessary for the diagnosis of cirrhosis, which requires a different follow-up than noncirrhotic diagnoses. In patients without cirrhosis, it is not necessary to screen for varices or hepatocellular carcinoma.

When cirrhosis is obvious in a patient with alcoholism and without severe liver disease, biopsy is not appropriate to justify the diagnosis of alcoholic hepatitis. Even if this statement seems logical, there are few studies in the literature estimating the 'obviousness' of cirrhosis. The following signs have potentially high positive predictive values: firm liver, ascites, splenomegalia, spider angioma, prothrombin time

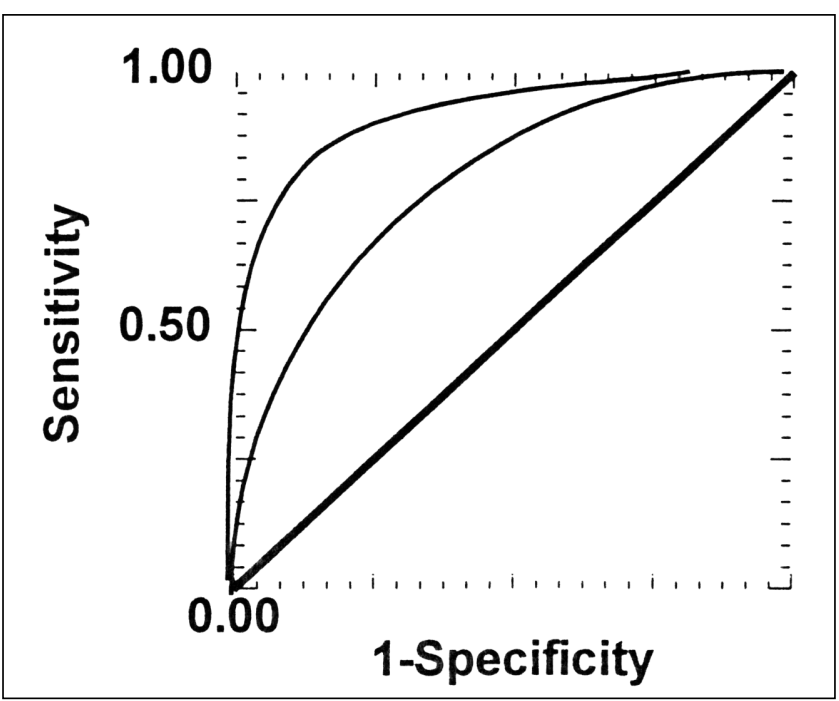

Figure 2) Ranges of sensitivity and specificity of cirrhosis markers in heavy drinkers. Alcoholic cirrhosis: ranges of sensitivity and specificity of PGA Prothrombin gamma glutamyl transpeptidase apolipoprotein A1; P-III-P Procollagen III peptide. Prothrombin, hyaluronic acid receiver operating characteristic curves. Data from references 30-35

lower than 60\%, low serum apolipoprotein-AI concentration, high serum hyaluronate and platelet count below 100,000 per $\mathrm{mm}^{3}$.

A reduction in the indications for biopsy in heavy drinkers may be achieved by increasing the positive predictive value and the negative predictive value of cirrhosis markers. 


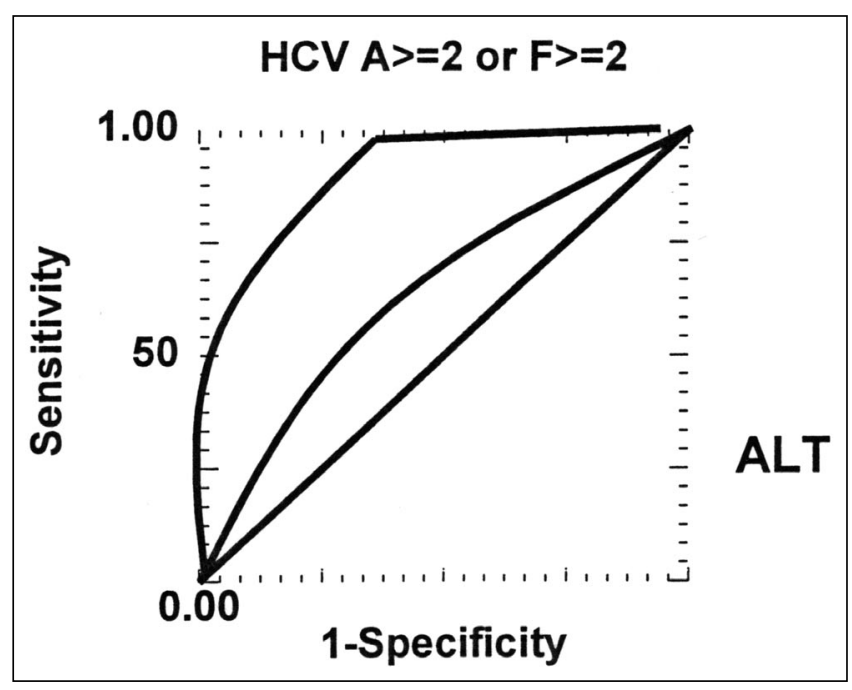

Figure 3) Chronic hepatitis C virus (HCV). Range of marker's sensitivity and specificity: receiver operating characteristic curves. A Activity grade; ALT Alanine aminotransferase; F Fibrosis stage. Data from references 39,40

Cirrhosis markers in heavy drinkers (32-35) are summarized in Figure 2.

Extremely complicated view: Acute alcoholic hepatitis exemplifies the complexity of appropriateness of evaluation.

The first difficulty is the possible variability of the histological definition because alcoholic hepatitis can be defined as the presence of hyalin necrosis, Mallory bodies and polynuclear infiltrate. Most often the presence of two features among these lesions is necessary, but this has not been validated.

The second difficulty is whether corticosteroids are recognized as an effective treatment of severe alcoholic hepatitis. There is a long history of corticosteroid efficacy evaluation. Since 1971, 13 randomized, clinical trials and six metaanalyses have been performed. The results among trials were discordant. Among the meta-analyses, there was only one that was not affected significantly by corticosteroids (36). In this meta-analysis, trials were weighted and the trial with the biggest weighting factor was the trial by Mendenhall et al (37). Unfortunately this trial was very different from others becuase $50 \%$ of patients did not have severe hepatitis and $68 \%$ did not have biopsy. Furthermore, the dose of corticosteroid used in the trial was lower than usual, with a decreasing regimen. The mean dose was $23 \mathrm{mg} /$ day of prednisolone versus $40 \mathrm{mg}$ in the other trial. Finally, after excluding the patients without severe diseases, the authors observed a significant effect with corticosteroids. After evaluating these different factors, it was concluded that liver biopsy is appropriate.

\section{APPROPRIATENESS OF LIVER BIOPSY IN CHRONIC HEPATITIS C}

Extremely simple view: In patients with chronic hepatitis C, liver biopsy may be considered inappropriate if the patient is hepatitis C-positive by polymerase chain reaction (PCR) and has abnormal serum transaminase levels. The indication of treatment by combination ribavirin and interferon, which has a $40 \%$ mean sustained response rate, may be considered mandatory.

Intermediate point of view: Recent consensus conferences have stated that liver biopsy is mandatory in patients with chronic hepatitis $\mathrm{C}$ with abnormal alanine aminotransferase (ALT) levels, permitting grading and staging of the disease $(1,38)$. It has been stated that liver biopsy should be performed before initiating treatment and that it is not known whether and when repeat biopsy is necessary.

Liver biopsy can assess the rate of disease progression when the date of contamination is known (fibrosis progression rate) and to improve the prediction of treatment response.

For diagnostic decisions, as discussed for alcoholic liver disease, biopsy may be viewed as necessary in order to diagnose cirrhosis, which may imply a different follow-up than in non-cirrhotic patients. In a patient with cirrhosis, it is necessary to screen for varices and hepatocellular carcinoma. When the cirrhosis is obvious in a patient with hepatitis C, biopsy is not appropriate. For patients with alcoholic liver disease, few studies have estimated the predictive values of clinical, biological (39-40) or morphological signs (41-42). The following signs have potentially high positive predictive values: firm liver, ascites, splenomegalia, spider angioma, prothrombin time lower than $60 \%$, high serum hyaluronate levels and platelet counts below 100,000 per $\mathrm{mm}^{3}$. With ultrasound, liver surface nodularity and reduction of portal flow velocity have better predictive values. A reduction of biopsy indication may be achieved by increasing the positive predictive value and the negative predictive value of cirrhosis markers. Cirrhosis markers in chronic hepatitis $\mathrm{C}$ are summarized in Figure 3.

Extremely complicated view: In patients with hepatitis C, the indication of liver biopsy is complicated. In patients with acute hepatitis $\mathrm{C}$, because of the effectiveness of treatment and the high (80\%) spontaneous evolution to a chronic disease, treatment seems mandatory. In chronic hepatitis C, liver biopsy is probably not mandatory in patients who can contaminate other people or in patients who have extrahepatic manifestations impairing quality of life. The issue is that the definition of these groups is complicated. It seems reasonable to consider that a cardiac surgeon who is hepatitis Cpositive by PCR is at risk of contaminating patients, but what about a nurse in a psychiatric ward? Should prostitutes be considered at risk of contaminating clients? Is an active intravenous drug user considered at risk of contaminating other intravenous drugs users? Another difficult issue is the definition of extrahepatic manifestations impairing the quality of life and related to hepatitis $C$ virus infection. In a cohort of 1614 patients (43), at least one clinical extrahepatic manifestation was observed in 1202 patients (74\%; 95\% CI 72 to 77). Five manifestations had a prevalence above $10 \%$, including arthralgia (23\%), paresthesia (17\%), myalgia (15\%), pruritus $(15 \%)$ and sicca syndrome (11\%). If treatment is effective for these symptoms, liver biopsy is not mandatory. Studies need to be performed to estimate which percentage of 
these symptoms are due to hepatitis $\mathrm{C}$ virus infection and what the efficacy of hepatitis $C$ treatment is.

Another issue is the diagnosis of minimal disease without biopsy. Among patients who are hepatitis C-positive by PCR with sustained, normal transaminase levels, despite a low median fibrosis progression rate, only $20 \%$ have a normal liver (no activity and no fibrosis) (44). Thirteen per cent of patients have extensive fibrosis (METAVIR stage 2, 3 or 4), for which treatment is mandatory. No markers exist to exclude patients with minimal disease.

One last common issue is the influence of other risk factors such as alcohol consumption. A liver biopsy may be considered appropriate in patients with hepatitis C who consume more than four drinks per day to differentiate the lesions related to alcohol or the virus.

\section{CONCLUSIONS}

Liver biopsy is used extensively, but its appropriateness has not been evaluated perfectly. Liver biopsy is appropriate for few diagnoses, and many stagings of chronic liver diseases such as alcoholic liver disease and chronic HCV. However, the appropriateness of liver biopsy in the practical algorithm of such diseases should be further evaluated. An excess use of liver biopsy, because of its cost and risk, may be a barrier to treatment. Underused liver biopsy may lead to inappropriate treatment of hepatitis.

\section{REFERENCES}

1. Perrillo RP. The role of liver biopsy in hepatitis C. Hepatology 1997;26:57S-61S.

2. Poynard T, Lebrec D. The inconvenience of investigations used in hepatology: patients' and hepatologists' opinions. Liver 1982;2:369. 75 .

3. von Frerichs. Uber den diabetes. Hirschwald, Berlin: 1884.

4. Schupfer F. De la possibilité de faire 'intra vitam' un diagnostic précis des maladies du foie et de la rate. Semin Med 1907;27:229-30.

5. Huard P. La ponction biopsie du foie et son utilité dans le diagnostic des affections hépatiques. Ann Anat Pathol 1935;12:1118-24.

6. Menghini G. One-second needle biopsy of the liver. Gastroenterology 1958;35:190-9.

7. Theodossi A, Spiegelhalter D, Portmann B, Eddleston AL, Williams R. The value of clinical, biochemical, ultrasound and liver biopsy data in assessing patients with liver disease. Liver 1983;3:31526.

8. Soloway RD, Baggenstoss AH, Schoenfield LJ, Summerskill WH. Observer error and sampling variability tested in evaluation of hepatitis and cirrhosis by liver biopsy. Am J Dig Dis 1971;16:1082-6.

9. Theodossi A, Skene AM, Portmann B, et al. Observer variation in assessment of liver biopsies including analysis by kappa statistics. Gastroenterology 1980;79:232-41.

10. Bedossa P, Poynard T, Naveau S, Martin ED, Agostini H, Chaput JC. Observer variation in assessment of liver biopsies of alcoholic patients. Alcohol Clin Exp Res 1988;12:173-8.

11. Intraobserver and interobserver variations in liver biopsy interpretation in patients with chronic hepatitis C. The French METAVIR Cooperative Study Group. Hepatology 1994;20:15-20.

12. Labayle D, Chaput JC, Albuisson F, Buffet C, Martin E, Etienne JP. [Comparison of the histological lesions in tissue specimens taken from the right and left lobe of the liver in alcoholic liver disease]. Gastroenterol Clin Biol 1979;3:235-40.

13. Pagliaro L, Rinaldi F, Craxi A, et al. Percutaneous blind biopsy versus laparoscopy with guided biopsy in diagnosis of cirrhosis. A prospective, randomized trial. Dig Dis Sci 1983;28:39-43.

14. Colombo M, Del Ninno E, de Franchis R, et al. Ultrasound-assisted percutaneous liver biopsy: superiority of the Tru-Cut over the Menghini needle for diagnosis of cirrhosis. Gastroenterology 1988;95:487-9.
15. Papini E, Pacella CM, Rossi Z, et al. A randomized trial of ultrasoundguided anterior subcostal liver biopsy versus the conventional Menghini technique. J Hepatol 1991;13:291-7.

16. Lindor KD, Bru C, Jorgensen RA, et al. The role of ultrasonography and automatic-needle biopsy in outpatient percutaneous liver biopsy. Hepatology 1996;23:1079-83.

17. Maharaj B, Maharaj RJ, Leary WP, et al. Sampling variability and its influence on the diagnostic yield of percutaneous needle biopsy of the liver. Lancet 1986;1:523-5.

18. Crawford AR, Lin XZ, Crawford JM. The normal adult human liver biopsy: a quantitative reference standard. Hepatology 1998;28:323-31.

19. Urena MA, Ruiz-Delgado FC, Gonzalez EM, et al. Assessing risk of the use of livers with macro and microsteatosis in a liver transplant program. Transplant Proc 1998;30:3288-91.

20. Gayral F, Potier M, Salmon R, Labayle D, Larrieu H. [Vascular complications of needle biopsy of the liver]. J Chir (Paris) 1979;116:261-4.

21. Lebrec D, Goldfarb G, Degott C, Rueff B, Benhamou JP. Transvenous liver biopsy: an experience based on 1000 hepatic tissue samplings with this procedure. Gastroenterology 1982;83:338-40.

22. Piccinino F, Sagnelli E, Pasquale G, Giusti G. Complications following percutaneous liver biopsy. A multicentre retrospective study on 68,276 biopsies. J Hepatol 1986;2:165-73.

23. McGill DB, Rakela J, Zinsmeister AR, Ott BJ. A 21-year experience with major hemorrhage after percutaneous liver biopsy. Gastroenterology 1990;99:1396-400.

24. Maharaj B, Bhoora IG. Complications associated with percutaneous needle biopsy of the liver when one, two or three specimens are taken. Postgrad Med J 1992;68:964-7.

25. Van Thiel DH, Gavaler JS, Wright H, Tzakis A. Liver biopsy. Its safety and complications as seen at a liver transplant center. Transplantation 1993;55:1087-90.

26. Janes $\mathrm{CH}$, Lindor $\mathrm{KD}$. Outcome of patients hospitalized for complications after outpatient liver biopsy. Ann Intern Med 1993;118:96-8.

27. Gilmore IT, Burroughs A, Murray-Lyon IM, Williams R, Jenkins D, Hopkins A. Indications, methods, and outcomes of percutaneous liver biopsy in England and Wales: an audit by the British Society of Gastroenterology and the Royal College of Physicians of London. Gut 1995;36:437-41.

28. Vivas S, Palacio MA, Rodriguez M, et al. Ambulatory liver biopsy: complications and evolution in 264 cases. Rev Esp Enferm Dig 1998;90:175-82.

29. Poynard T, Ramond MJ, Rueff B, Mathurin P, Chaput JC, Benhamou JP. Corticosteroids reduce mortality from alcoholic hepatitis in patients without encephalopathy. A meta-analysis of randomized control trials. Hepatology 1991;14:234A. (Abst)

30. Ramond MJ, Poynard T, Rueff B, et al. A randomized trial of prednisolone in patients with severe alcoholic hepatitis. N Engl J Med 1992;326:507-12.

31. Mathurin P, Duchatelle V, Ramond MJ, et al. Survival and prognostic factors in patients with severe alcoholic hepatitis treated with prednisolone. Gastroenterology 1996;110:1847-53.

32. Talley NJ, Roth A, Woods J, Hench V. Diagnostic value of liver biopsy in alcoholic liver disease. J Clin Gastroenterol 1988;10:647-50.

33. Poynard T, Aubert A, Bedossa P, et al. A simple biological index for detection of alcoholic liver disease in drinkers. Gastroenterology 1991;100:1397-402.

34. Teare JP, Sherman D, Greenfield SM, et al. Comparison of serum procollagen III peptide concentrations and PGA index for assessment of hepatic fibrosis. Lancet 1993;342:895-8

35. Oberti F, Valsesia E, Pilette C, et al. Noninvasive diagnosis of hepatic fibrosis or cirrhosis. Gastroenterology 1997;113:1609-16.

36. Christensen E, Gludd C. Glucocorticosteroids are ineffective in alcoholic hepatitis: a meta-analysis adjusting for confounding variables. Gut 1995;37:113-8.

37. Mendenhall CL, Anderson S, Garcia-Pont P, et al. Short-term and long-term survival in patients with alcoholic hepatitis treated with oxandrolone and prednisolone. N Engl J Med 1984;311:1464-70.

38. EASL International Consensus Conference on Hepatitis C. Paris, 2628, February 1999, Consensus Statement. European Association for the study of the Liver. J Hepatol 1999;30:956-61.

39. Poynard T, Bedossa P. Age and platelet count: a simple index for 
predicting the presence of histological lesions in patients

with antibodies to hepatitis $C$ virus. METAVIR and

CLINIVIR Cooperative Study Groups. J Viral Hepat 1997:4:199-208

40. Bonacini M, Hadi G, Govindarajan S, Lindsay KL. Utility of a discriminant score for diagnosing advanced fibrosis or cirrhosis in patients with chronic hepatitis C virus infection. Am J Gastroenterol 1997;92:1302-4.

41. Gaiani S, Gramantieri L, Venturoli N, et al. What is the criterion for differentiating chronic hepatitis from compensated cirrhosis?
A prospective study comparing ultrasonography and percutaneous liver biopsy. J Hepatol 1997;27:979-85.

42. Aube C, Oberti F, Korali N, et al. Ultrasonographic diagnosis of hepatic fibrosis or cirrhosis. J Hepatol 1999;30:472-8.

43. Cacoub P, Poynard T, Ghillani P, et al. Extrahepatic manifestations in patients with chronic hepatitis C. Arthritis Rheum 1999;42:2204-12.

44. Mathurin P, Moussalli J, Cadranel JF, et al. Slow progression rate of fibrosis in hepatitis $\mathrm{C}$ virus patients with persistently normal alanine transaminase activity. Hepatology 1998;27:868-72. 


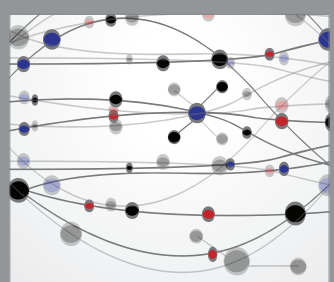

The Scientific World Journal
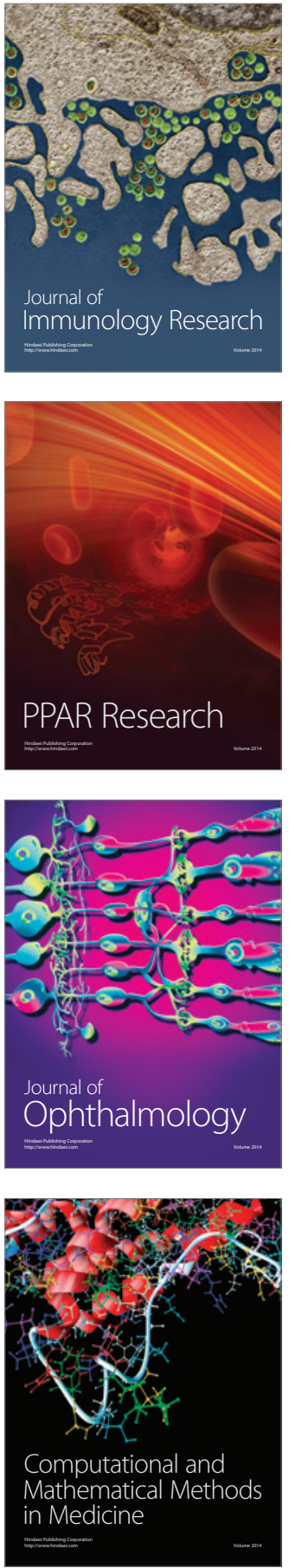

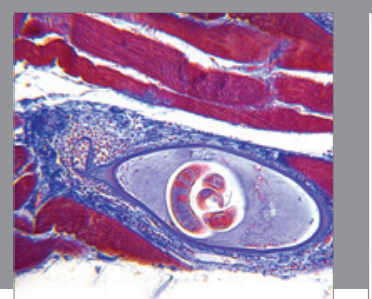

Gastroenterology Research and Practice

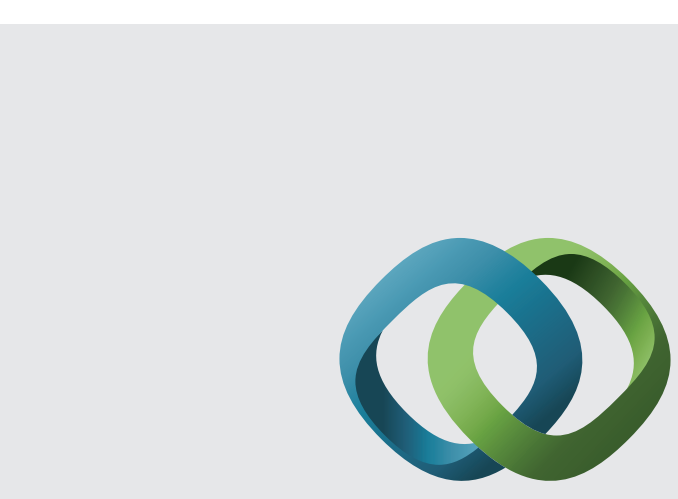

\section{Hindawi}

Submit your manuscripts at

http://www.hindawi.com
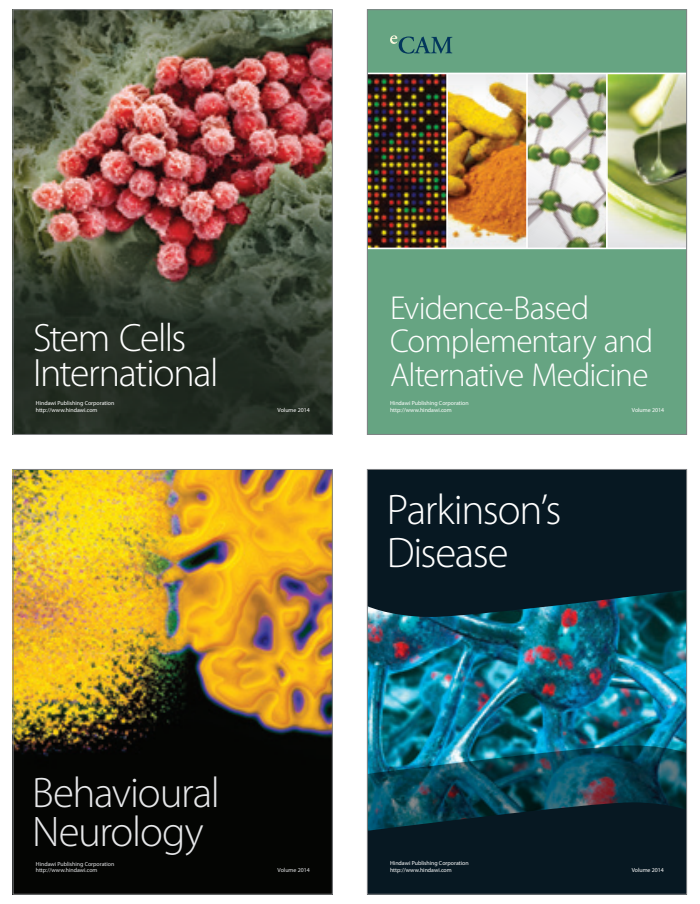
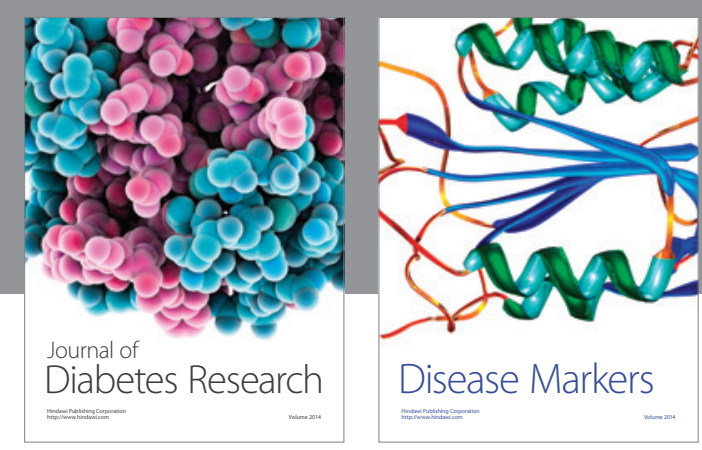

Disease Markers
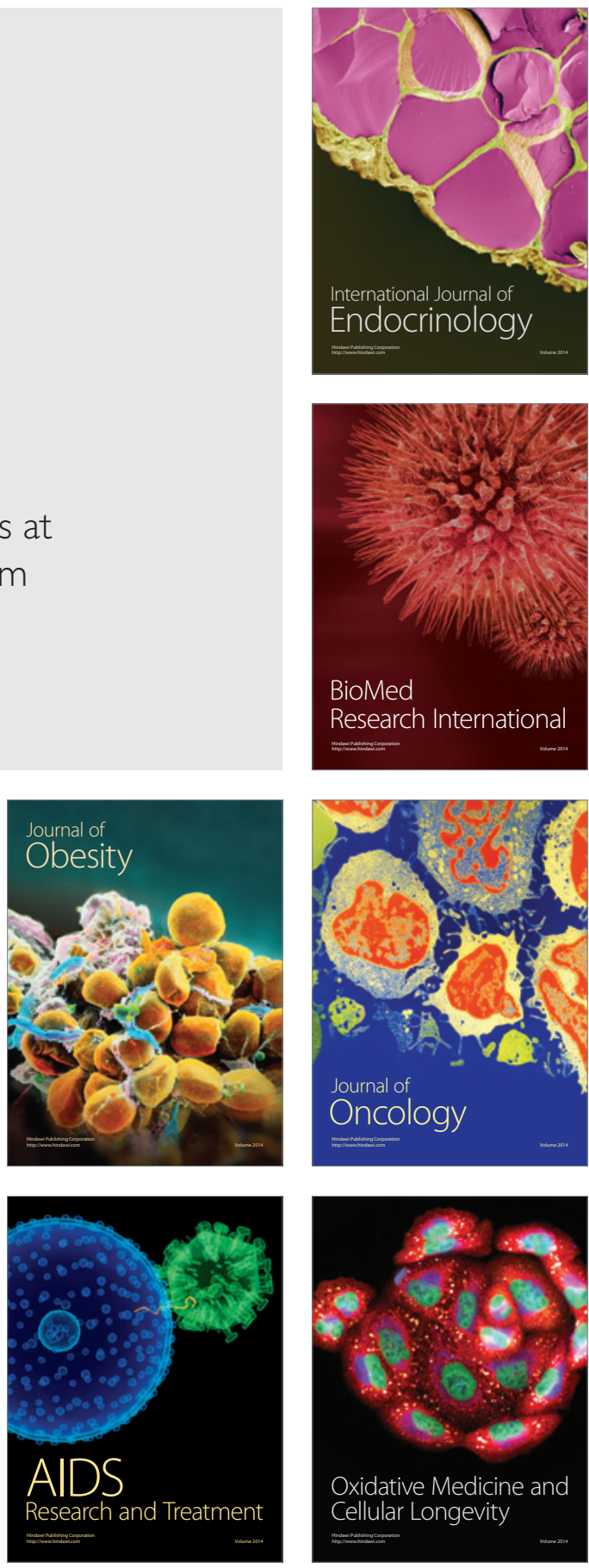